WIENER SLAVISTISCHES JAHRBUCH, Band 53/2007, 91-107

(C) 2007 by Österreichische Akademie der Wissenschaften, Wien

A NDREAS LEBEN

\title{
Probleme der Autobiographieforschung im slowenischen Kontext
}

\begin{abstract}
Članek obravnava razvoj diskusije o slovenskem avtobiografskem pisanju v literarni vedi ter v etnologiji in sociologiji v slovenskem kontekstu, za katerega sta značilna razmeroma pozno tematiziranje avtobiografske problematike $\mathrm{v}$ znanstvenem diskurzu in komaj razvita interdisciplinarna komunikacija. Zanimanje za avtobiografsko pisanje sicer narašča, vendar novejša dognanja še niso zapustila vidnejših sledi v literarni teoriji, literarni zgodovini, učbenikih in priročnikih, kar opozarja na potrebo po širše, intradisciplinarno zasnovani razpravi o slovenski avtobiografiji, ki bi lahko omogočila tudi njeno boljše vključevanje v mednarodni diskurz.
\end{abstract}

Noch vor knapp zwei Jahrzehnten hat sich die Literaturwissenschaft in Slowenien mit der Autobiographie kaum befasst, und auf den ersten Blick sind auch seitdem nur wenige Arbeiten zum Thema erschienen; ein Standardwerk zur slowenischen Autobiographie ist ebenso ausständig wie ein slowenisches Nachschlagewerk zur Autobiographietheorie. Lenkt man aber den Blick in die Tiefe und zieht man auch die benachbarten Disziplinen heran, zeigt sich dennoch, dass seit einigen Jahren durchaus eine merkliche Auseinandersetzung mit dem Thema stattfindet, die es gerechtfertigt erscheinen lässt, von einer slowenischen Autobiographieforschung zu sprechen. Ich werde im Folgenden kursorisch auf die wichtigsten dieser Arbeiten eingehen, sie vor dem Hintergrund der internationalen Autobiographiediskussion miteinander in Beziehung setzen und versuchen, aktuelle Problemfelder und mögliche Perspektiven der slowenischen Autobiographieforschung aufzuzeigen.

Im internationalen Rahmen setzt die Autobiographieforschung um 1900 ein, insbesondere in Deutschland, Frankreich, England und den Vereinigten Staaten, die Günther Niggl als die Kernländer der diesbezüglichen Forschung bezeichnet (Niggl 1998: 593). Im deutschen Sprachraum etablierte sich die Autobiographieforschung in den sechziger Jahren, in den anglophonen und frankophonen Ländern schon etwas früher. Seit den achtziger Jahren weitet sie sich europaweit und über Europa hinausgehend aus und ist in ihrer Fülle längst nicht mehr überschaubar. 
In der slowenischen Literaturwissenschaft gab es, streng genommen, bis Ende der achtziger Jahre weder eine wirkliche Auseinandersetzung mit der Autobiographie noch mit ihren theoretischen Grundlagen, wenngleich namhafte Autoren und Autorinnen wie Janez Trdina, Jakob Alešovec, Ivan Cankar, Stanko Majcen, Ivan Mrak, Miran Jarc, Juš Kozak, Vladimir Bartol, Vladimir Kralj, Mira Mihelič, Boris Pahor, Igor Torkar, Jože Javoršek, Taras Kermauner, Marjan Rožanc, Vitomil Zupan, Lojze Kovačič oder Žarko Petan eine Reihe höchst unterschiedlicher autobiographischer Texte verfassten. Es wäre zu kurz gegriffen, das lange kaum vorhandene Interesse an diesem Forschungsbereich allein auf die Problematik der Wertung, der oft unterstellten künstlerischen Minderwertigkeit autobiographischen Schreibens zurückzuführen, vielmehr ist dieses Phänomen auch im Lichte des vormals generell geringen Theorieinteresses innerhalb der slowenischen Geisteswissenschaften zu betrachten, das Dušan Pirjevec schon 1968 bemängelte (Pirjevec 1991: 11). Dies scheint in besonders hohem Maß und bis in die jüngste Zeit gerade die Literaturwissenschaft zu betreffen, machte doch Miran Štuhec noch vor wenigen Jahren darauf aufmerksam, dass in der slowenischen Literaturtheorie, anders als in der Linguistik, ein bedeutender Teil der internationalen theoretischen Überlegungen kaum Spuren hinterlassen habe. Štuhec begründete dies damit, dass die slowenische Literatur in der Vergangenheit auf die Erhaltung der nationalen Existenz ausgerichtet gewesen sei und die Literaturgeschichte vor allem nach dem „Volksgeist“ und dem ,ethnischen Charakter" der Literatur gesucht habe (Štuhec 2000: 11-13).

Vor dem Hintergrund, dass die nationalkonstitutive und nationalaffirmative Funktion von Literaturwissenschaft, Literaturgeschichte und auch eines Teils der slowenischen literarischen Produktion bis in die neunziger Jahre hinein dominant war, wird verständlich, warum man dem autobiographischen Schreiben über ganze literarische Epochen hinweg kaum Aufmerksamkeit schenkte. Die Metaphorik des Kollektivs stellte die Metaphorik des Individuums gleichsam in den Schatten. Hierin ist auch die Erklärung dafür zu suchen, warum der Begriff Autobiographie, der 1898 erstmals als Bezeichnung für eine Textgattung bzw. ein literarisches Genre in der slowenischen Literaturkritik genannt wird, schon zu Anfang nur ein geringes Echo auslöste und insbesondere in der Zeit nach dem Zweiten Weltkrieg in der Kritik kaum präsent war (Belšak 2003: 159).

Ein weiterer Grund für das geringe Interesse an der Autobiographie ist in der langen Vorherrschaft des slowenischen literaturwissenschaftlichen Positivismus zu sehen. Vor allem ausgehend von den Jagić-Schülern Ivan Prijatelj und France Kidrič sowie deren Schülern Mirko Rupel, Lino Legiša, Alfons Gspan, Marja Boršnik, Fran Petrè und Boris Merhar, war die slowenische Literaturgeschichte bis Mitte der fünfziger Jahre im weitesten Sinn positivistisch orientiert. Auch Anton Ocvirk, der die Grundlagen für die slowenische vergleichende Literaturgeschichte und Literaturtheorie schuf, in deren Richtung neben Prijatelj und Kidrič bereits der MiklošičSchüler und spätere Jagić-Mitarbeiter Matija Murko gearbeitet hatte, blieb methodologisch der exakten historischen empirischen Forschung und damit dem Positivis- 
mus verpflichtet. Der nachhaltige Erfolg des späten slowenischen Positivismus ist darauf zurückzuführen, dass seine Möglichkeiten und seine soziale Funktion noch lange nicht ausgeschöpft waren, da es sich bei den außerliterarischen Bereichen der Kultur, Politik und Sozialgeschichte, in die der literaturwissenschaftliche Positivismus eingriff, um defizitäre Bereiche handelte, weshalb die Literaturgeschichte vielfach die fehlenden Kapitel einer slowenischen Universalgeschichte ersetzen oder zumindest ergänzen musste und die nationale Ideologie zu einem elementaren Teil der positivistischen Literaturwissenschaft wurde (Dolinar 1978: 114, 118).

Da sich der Positivismus nicht zuletzt mit der Lebensgeschichte bekannter Persönlichkeiten auseinander setzte, läge die Vermutung nahe, dass er auch die Autobiographieforschung hätte beflügeln müssen. Beflügelt wurde jedoch lediglich die Biographieforschung, indem man mit Hilfe der biographischen Methode Wesen, Werk und Leben von Schriftstellern - nur selten auch von Schriftstellerinnen - zu erklären oder zu interpretieren versuchte. Rückblickend ließe sich sogar sagen, dass das Bemühen um Faktentreue und genaue Recherche, vor allem in der Literaturgeschichtsforschung, die Frage nach dem Autobiographischen im Sinne eines Hilfsmittels bereits zu beantworten schien, ohne die mit dem autobiographischen Schreiben verknüpften Problemkomplexe thematisiert $\mathrm{zu}$ haben. Biographien wurden außerdem weit häufiger, höher und milder beurteilt als Autobiographien, so dass sich schon in der Zwischenkriegszeit im Bewusstsein der Kritik die Biographie als „,künstlerische Erzählung über eine bekannte Persönlichkeit“ etablieren konnte und in den sechziger Jahren zwei große slowenische Verlage - Državna založba Slovenije und Prešernova založba - in eigenen Buchreihen slowenische und übersetzte Biographien zu edieren begannen (Belšak 2003: 155). Der höhere Rang der Biographie gegenüber der Autobiographie schlägt sich in der ungebrochenen Beliebtheit biographischer Romane bis in die Gegenwart nieder. ${ }^{1}$

Angesichts der vorherrschenden biographischen Praxis ist es nicht verwunderlich, dass von der Jahrhundertwende bis in die späten sechziger Jahre hinein die Auseinandersetzung mit autobiographischen Texten die Ausnahme blieb ${ }^{2}$ und selbst in diesen Beiträgen das Interesse an der Person des Verfassers im Vordergrund stand. ${ }^{3}$ Nach dem Zweiten Weltkrieg ist in der Publizistik und in Buchrezensionen

${ }^{1}$ Man denke an Ivan Pregeljs Roman über Simon Jenko (1924), an Anton Slodnjaks biographische Romane über Prešeren, Levstik und Cankar, die er in den dreißiger, vierziger und siebziger Jahren verfasste, an Ilka Vaštes biographischen Roman über France Prešeren. Diese Tradition findet ihre Fortsetzung in den Romanen von Mimi Malenšek (über Dragotin Kette und Josip Murn), Silvo Fatur (über Dragotin Kette), Ivan Sivec (über Anton Aškerc) und jüngst bei Milan Dekleva (über Slavko Grum).

2 Der Zettelkatalog literarischer Begriffe (Listkovni katalog literarnih pojmov) im ZRC der Slowenischen Akademie der Wissenschaften, der auf Exzerpten aus slowenischen Periodika von den Anfängen bis 1970 beruht, weist für diesen Zeitraum nur knapp 50 Einträge zum Bereich der Autobiographie auf.

3 Ivo Brnčič versuchte Ende der dreißiger Jahre mit psychologisch-spekulativen Interpretationen anhand von autobiographischen Aspekten in einigen Texten Ivan Cankars vermeintliche Persönlichkeitsstörungen und pubertäre Komplexe des Autors darzulegen. Vgl. 
im Zusammenhang mit France Prešeren, Primož Kozak, Ivan Cankar, Prežihov Voranc und Edvard Kocbek nur nebenbei von autobiographischen Elementen die Rede. ${ }^{4}$ Als erste einschlägige Auseinandersetzung mit Autobiographik nach dem Zweiten Weltkrieg ist die auf Serbokroatisch verfasste Diplomarbeit von Marija Mitrović über die Prosa Juš Kozaks zu nennen ${ }^{5}$ bzw. ihr auf diese Arbeit zurückgehender Aufsatz aus dem Jahr 1967 (vgl. Mitrović 1967).

Diese zögerliche Entwicklung, die erst seit Ende der achtziger Jahre allmählich überwunden wird, zeigt, dass auch die Methoden des Formalismus und Strukturalismus, die den Positivismus in den sechziger Jahren ablösten, das Forschungsinteresse an der Autobiographie nicht wesentlich steigern konnten. Trotz des methodischen Paradigmenwechsels blieb die Autobiographie im slowenischen literaturwissenschaftlichen, von der Historiographie und Geschichtsphilosophie geprägten Autobiographieverständnis, eine nichtliterarische, höchstens ,halbliterarische“ Gattung oder Mischform, die der Biographik oder der Memoiristik zugeordnet wurde (vgl. Pregelj: 1936, 90; Trdina 1978: 275-276; Kmecl 1976, 306-308). Da in der traditionell ästhetizistisch orientierten, nunmehr textimmanent vorgehenden Literaturwissenschaft das Einschreiben zu zahlreicher Segmente gesellschaftlicher Wirklichkeit in einen (literarischen) Text als künstlerisch minderwertig galt, wurde auch die Autobiographie meist als künstlerisch minderwertige Form betrachtet (Koron 2003a, 193-194). Als zentrales Argument diente das auf Aristoteles zurück gehende Mimesisprinzip, demzufolge die poetischen Gattungen nachahmenden Charakter hätten und in diesem Sinn Fiktion und damit Literatur seien, während die Abbildung von Wirklichkeit als Sache der Geschichtsschreibung aufzufassen sei und dem Bereich des Dokumentarischen, Nichtfiktionalen, Faktischen zugewiesen werden müsse. Der „linguistic turn“, der Ende der sechziger Jahre die westliche Autobiographieforschung nachhaltig beeinflusste und den Weg zur Dekonstruktion öffnete, blieb im slowenischen Kontext aus. Im Gegenteil, die ästhetischen Vorbehalte gegenüber der Autobiographie und dem autobiographischen Schreiben scheinen vielfach bis in die Gegenwart nachzuwirken, zumal die slowenische Literaturwissenschaft sich seit Mitte der achtziger Jahre intensiv mit der Frage der literarischen Gattungen und

Ivo Brnčič, Cankarjeva ljubezenska drama, Modra ptica, 1939-40, 125-133, 157-163, 202-212; ders., Problem mladosti v Cankarjevi duševnosti in literaturi, Modra ptica, 1939-40, 335-344, 349-353.

${ }^{4}$ Vgl. Anton Slodnjak, „Prekop“ - „Krst pri Savici“ - „Neiztrohnjeno srce“, Novi svet, 1949, 206; Josip Vidmar, Juš Kozak. Lesena žlica I. in II. del, Novi svet, 1952, 2. Buch, 1136; Dušan Pirjevec, Ideje, ocene, metoda, Naši razgledi, 1959/12, 288-290; Ignac Kamenik, Materin delež v Cankarjevem literarnem opusu, Jezik in slovstvo, 1959-60/5, 154; Franc Zadravec, Kranjčev roman Do zadnjih meja, Jezik in slovstvo, 1959-60/6, 163; Marjan Kramberger, Problemi kmetstva v Prežihovih novelah, Perspektive, 1960-61/5, 596; Ignac Kamenik, Otroški liki v delih Ivana Cankarja, Jezik in slovstvo, 1961-62/3, 7882; Franc Zadravec, Slovenska idealistična nova stvarnost, Sodobnost, 1966/2, 178.

5 Vgl. Marija Gleščić-Mitrović, Autobiografski elementi u delima Juša Kozaka, Ljubljana, o. J. 
Genres befasst, die Autobiographie und Autobiographik aber nur selten in ihre Überlegungen einbezieht, auch wenn etwa mit Franjo Frančič, Nedeljka Pirjevec, Marija Vogrič, Manca Košir, Jože Snoj und Ciril Zlobec die Zahl der Autorinnen und Autoren weiter zunimmt, die diesem Bereich zuordenbar sind. ${ }^{6}$

Wie eingangs erwähnt, repräsentiert die Literaturwissenschaft nur einen Teil der slowenischen Autobiographieforschung. Sie ist außerdem nicht allein auf die Slowenistik und Komparatistik beschränkt, sondern die Germanistik und andere Philologien sind, nebst Geschichte, Soziologie, Ethnologie und anderen Disziplinen, hier ebenso von Belang. Schon dieser flüchtige Entwurf macht deutlich, dass die Autobiographieforschung grundsätzlich den Rahmen eines nationalen Literaturverständnisses sprengt, dass sie sich für die interdisziplinäre Forschung besonders eignet und etwa auch bei der jüngst von Marko Juvan (2006: 47) vorgeschlagenen Umbildung der Literaturtheorie zu einer Theorie des literarischen Diskurses eine wichtige Rolle spielen kann. Allerdings ist gerade innerhalb der slowenischen Literaturwissenschaft das Interesse an der Autobiographieforschung nach wie vor wenig ausgeprägt, was auch an der jüngeren Forschungsgeschichte abzulesen ist.

Matjaž Kmecl ging als Mitautor der ersten Monographie über die slowenische Nachkriegsliteratur zumindest am Rande auf das Problem der Autobiographik ein, ordnete aber in seiner Darstellung der Erinnerungsliteratur ehemaliger Partisanen den autobiographischen Anteil dieser Texte nahezu völlig der historiographischen Perspektive unter (vgl. Kmecl 1967: 363-379, insbes. 373, 377). In Einklang damit ist auch in Kmecls mehrfach aufgelegtem literaturwissenschaftlichen Lexikon kein Stichwort zur Autobiographie zu finden, sondern lediglich ein Eintrag zu den Erinnerungen bzw. Memoiren (Kmecl 1976: 305-306).

Die Erinnerungsliteratur, sowohl jene über den Partisanenwiderstand als auch über andere einschneidende historische Ereignisse, wurde in den siebziger und achtziger Jahren zunächst vor allem von studentischer Seite thematisiert. ${ }^{7}$ Wie in diesen

${ }^{6}$ Vgl. Janko Kos, Morfologija literarnega dela, Ljubljana: DZS, 1981; ders., Roman, Ljubljana: DZS, 1983; ders., Literarne tipologije, Ljubljana: DZS, 1989; Miran Hladnik, Slovenska kmečka povest, Ljubljana: Prešernova družba, 1990; ders., Trivialna literatura, Ljubljana: DZS, 1983; Igor Škamperle, Dnevnik kot oblika literarnega pisanja, Diplomska naloga, Ljubljana 1990; Metka Kordigel, Znanstvena fantastika, Ljubljana: DZS, 1994; Aleksandra Bizjak, Pridiga kot žanr, Ljubljana: Založba ZRC, ZRC SAZU, 2005; weiters Juvan $(2002,2006)$.

${ }^{7}$ Folgende Arbeiten sind hier zu nennen: Majda Bavcon-Potrata, Grabeljškov doživljajski in pripovedni svet (poskus vsebinske, idejne in oblikovne razčlenitve besedil Karla Grabeljška - Gabra), Diplomska naloga, Maribor 1974; Daniela Sintič-Klasinc, Partizanska spominska proza, Diplomska naloga, o. O. 1974/75; Rozalija Tinev-Pečarič, Monografija: Hinko Dolenec, Diplomska naloga, Škofije 1975; Andreja Ceglar, Kavčič Vladimir: Vaška komanda, Kaj je povedal ded, Referat, o. O., o. J.; Vida Petaci-Ifko, Stanko Cajnkar, Diplomska naloga, Ljubljana 1980/81; Martina Kukovičič, Novelistika Vladimira Kralja, Diplomska naloga, Brestanica o. J.; Irena Puhar, Otroška perspektiva v pripovedništvu Marjana Rožanca, Diplomska naloga, Ljubljana 1982; Branka Pintar-Čenčič, Proza Ivana Ribiča, Diplomska naloga, Ljubljana 1983; Milena Laba-Stajčić, Pripoved lirskega značaja v dveh delih Miška Kranjca: Mladost v močvirju in Strici so mi povedali, 
Arbeiten bleibt auch in den Studien von France Bernik und Marjan Dolgan, die sich in einem langjährigen Projekt mit der slowenischen literarischen Kriegsprosa der Jahre 1941-1980 befassten, das autobiographische Moment im Hintergrund, bei letzteren sogar in zweifacher Hinsicht: zum einen gegenüber der historiographischen Perspektive, zum anderen gegenüber dem favorisierten Kriterium der Fiktionalität. Dies führt beispielsweise dazu, dass Bernik den vielbeachteten Roman Nekropola (1967) von Boris Pahor als „Erinnerungstext“ klassifiziert und aus den weiteren Betrachtungen ausschließt (Bernik - Dolgan 1988: 248). Dolgan machte zwar an anderer Stelle auf die Ambivalenz von Faktographie und Fiktionalisierung in der noch wenig erforschten slowenischen Erinnerungsliteratur und autobiographischen Prosa aufmerksam (Dolgan 1996: 40-41), wandte sich dann aber anderen Themen zu, sodass der Bereich der Kriegserinnerungen für die Autobiographieforschung noch immer ein breites Betätigungsfeld bietet, was im übrigen für die gesamte, dem Bereich der Erinnerungen oder Memoiren zugewiesene Literatur gilt.

France Bernik befasste sich in den achtziger Jahren außerdem mit der Autobiographik im Werk Ivan Cankars. Er ging dabei von einem traditionellen Autobiographieverständnis aus und bezog die europäische Autobiographieforschung in seine Überlegungen kaum ein, zumal er vor allem typlogische und narratologische Aspekte der Cankarschen Prosa analysierte und ihm daran gelegen war zu zeigen, wie Cankar außerliterarische Wirklichkeit zu höherer, möglicher Wahrheit umgeformt habe (vgl. Bernik 1983: 161, 215-216; Bernik 1987, 206-216).

Markieren Berniks Arbeiten den Beginn der Auseinandersetzung mit dem Problem von Autobiographik und Literatur, so ging Miran Hladnik in seinem Aufsatz über Stanko Majcens autobiographisches Fragment Detinstvo bereits von einem klaren, auf Ilse Aichinger rekurrierenden theoretischen Standpunkt aus und thematisierte nicht nur die Problematik des Fiktionalen und Faktischen, sondern auch Fragen des Wahrheits- und Subjektbegriffs (Hladnik 1989: 463-469).

In den Arbeiten von Franc Zadravec spielt das Autobiographische an sich nur eine untergeordnete Rolle, allerdings konzipierte er 1991 in einem Aufsatz über den Ich-Erzähler im slowenischen Roman drei Formen des Ich-Erzählers, darunter den ,autobiographischen“ oder „konkreten“ Ich-Erzähler. Dieser erzähle von einem „reifen Punkt" aus über sich, sein Umfeld und die Zeit, wobei er die Namen empirisch belegbarer Personen, Räume und Ereignisse verwende. Um „reine Literatur“ handle es sich dabei nur, wenn ein erfundener Ich-Erzähler autobiographische Fiktion und Dokument miteinander verbinde (Zadravec 1991: 51-56). Dieses Modell nahm Zadravec auch in seine dreibändige Monographie zum slowenischen Roman im 20. Jahrhundert auf (Zadravec 1997, 2002, 2005).

Diplomska naloga, o. O. 1983; Elen Pogačnik, Spominska proza Milana Gučka, Diplomska naloga, o. O. 1984; Nada Beguš, Pisateljsko delo Karla Leskovca, Diplomska naloga, Škofja Loka 1986. 
Die erste umfangreichere, gänzlich der Autobiographie gewidmete Studie ist die komparatistische Diplomarbeit von Dejan Pušenjak aus dem Jahr 1990. Pušenjak entwirft darin eine Geschichte der europäischen Autobiographie, bespricht die Verwendung des Begriffs in Slowenien und wirft provokant die Frage auf, ob es nicht doch vielleicht slowenische Autobiographien gebe, diese aber aufgrund mangelnder empirischer Forschungen über Wesen und Theorie der Autobiographie von den verwandten Gattungen, vor allem den Memoiren und autobiographischen Romanen, nicht unterschieden würden, oder ob das autobiographische Schaffen, bei Kenntnis des europäischen Autobiographieverständnisses, aufgrund der besonderen kulturellen, politischen und gesellschaftlichen Entwicklung in Slowenien, keine Verbreitung gefunden habe (Pušenjak 1990: 1). Pušenjak, der von einem historisch begründeten Gattungsverständnis ausgeht, das die Ganzheit eines beschriebenen Lebens als Gattungskriterium heranzieht, verneint letztlich diese Frage. Infolge dessen findet er in der slowenischen Literatur nur Reste ihrer zerfallenen Form im autobiographischen Roman, in der essayistischen Prosa, in Tagebüchern und Memoiren (Pušenjak 1990: 26-27, 55-57, 60). Die konsequente Argumentation hinsichtlich der Nichtexistenz slowenischer Autobiographie als (historischer) Gattung korreliert mit der Haltung von Janko Kos, dem Betreuer dieser Arbeit, der seinerseits in seinem Lexikon zur Theorie des Romans 151 Romangattungen anführt, ohne dabei jene des autobiographischen Romans überhaupt zu nennen (Kos 1983).

Behandeln die bisher genannten Studien vor allem die literarische Autobiographik, so bezieht Igor Grdina in seiner Diplomarbeit (1991) und seiner Dissertation (1994) ,echte“ Autobiographien in die Darstellung mit ein. Die beiden Arbeiten liefern in der Zusammenschau den ersten und bislang einzigen Ansatz zu einer Geschichte der slowenischen Autobiographie von den Anfängen bis in die neunziger Jahre des 20. Jahrhunderts, wurden aber nur in Form einiger ausgewählter Kapitel der breiteren Öffentlichkeit zugänglich gemacht. ${ }^{8}$ In Anlehnung an Kmecl positioniert Grdina die slowenische Autobiographie im Bereich schriftlicher wie mündlicher Erinnerungen. Die Beziehung von Autobiographie und Literatur sieht er im Kriterium der Fiktionalität begründet, wobei er das Untersuchen autobiographischer Romane und Erzählungen eher den „Breiten des Romans“ zuweist als den „Rändern der Autobiographie“ (Grdina 1991: 45-46). Im enzyklopädischen Stichwort am Ende seiner Diplomarbeit billigt Grdina der Autobiographie literarisches Potential und die Durchlässigkeit zu anderen Gattungen zu, auch zur Dichtung, verbindet sie aber zugleich mit rigiden Vorstellungen über den Bau und die Merkmale autobiographischer Texte, etwa bezüglich der Nichtfiktionalität des Stoffs, der Entwicklung der

\footnotetext{
${ }^{8}$ Vgl. Igor Grdina, Avtobiografija pri Slovencih v drugi polovici 19. stoletja, Slavistična revija, 1992/4, 341-363, ders., Avtobiografsko in avtotematsko v Prešernovem opusu, Celjski zbornik (1993), 327-332, ders., Dve avtobiografski pričevanji v nemščini. O avtobiografskih spisih Alme M. Karlin (1889-1950) in dr. Fritza Zanggerja (1877-1939) - o položaju nemško govorečih ljudi v slovenskih deželah po letu 1918, Celjski zbornik (1994), 197-205.
} 
Persönlichkeit, der straffen Komposition und einer klaren Lebensausrichtung (Grdina 1991: 203-204). In seiner Dissertation, in der „literarische Autobiographien“ in den Mittelpunkt der Betrachtungen rücken, ${ }^{9}$ wendet er sich praktischen Problemen der Gattung zu und berücksichtigt nun auch einen Teil der neueren internationalen Literatur zur Autobiographieforschung. Die erwähnte Autobiographiedefinition Grdinas übernahm Drago Bajt, der die Autobiographie den ,halbkünstlerischen Gattungen“ zuordnete und vom autobiographischen Roman trennte, in sein Handbuch für Textarbeiter (Bajt 1993, 123-125).

Einen qualitativen Sprung und Neuansatz in der Auseinandersetzung mit Autobiographie bedeutet der Aufsatz der Komparatistin Alenka Koron aus dem Jahr 1991. Koron fasst darin die internationalen und nationalen Forschungsergebnisse zusammen, thematisiert die Frage der Autobiographie als literarisches Genre und vermeint, bereits Anzeichen für den Beginn eines Kanonisierungsprozesses „nicht-fiktionaler künstlerischer Prosa“ zu erkennen. ${ }^{10}$ Anhand des Werks von Lojze Kovačič, mit dem sie sich in den folgenden Jahren immer wieder befasst (vgl. Koron 1995, 1999), untersucht sie, wie die Grenzen zwischen Autobiographie und Roman wirksam untergraben werden und die Autobiographie sich den Strukturen des modernen Romans nähern kann und umgekehrt. Davon ausgehend entwickelt sie in mehreren Aufsätzen ihren Vorschlag zur Einführung der „weichen“ Genrebezeichnung „Roman als Autobiographie“ (Koron 1998, 2003a, 2003b, 2006).

${ }^{9}$ Grdina nimmt Bezug auf Texte von I. Cankar, P. Kozak, F. Milčinski, S. Majcen, I. Mrak, I. Šorli, J. Mlakar, F. S. Finžgar, F. Bevk, M. Kranjec, B. Pahor, J. Javoršek, I. Torkar, T. Kermauner, M. Rožanc, M. Mihelič, J. Vidmar, Ž. Petan, L. Kovačič, ebenso auf die deutsch schreibende A. M. Karlin, den englisch schreibenden US-Emigranten Louis Adamič, die Emigranten Ciril Žebot, Albin Prepeluh, Ljubo Sirc, Vladimir Vauhnik, France Papež und Lev Detela, berücksichtigt aber ebenso die Tagebücher von Edvard Kocbek, Anton Novačan, Tone Fajfar, Makso Šnuderl, Izidor Cankar und Stane Kavčič sowie Politikerautobiographien (S. Vošnjak, H. Tuma) und Berufsautobiographien (M. Murko, M. Vidmar, A. Dermota, L. Korošec).

10 Aus dem literaturwissenschaftlichen Bereich führt Koron (1991: 63-64) folgende Artikel und Arbeiten an: Darinka Jocić-Ambrož, Avtobiografska proza Lojzeta Kovačiča, Slavistična revija, 1978/2, 177-192; France Bernik, Avtobiografični liki v Cankarjevi pripovedni fikciji, Slavistična revija 1980/3, 271-296; ders., Avtobiografsko v novejši slovenski vojni prozi. Tipologija pripovednih položajev, Sodobni slovenski jezik, književnost in literatura, Filozofska fakulteta, Ljubljana 1988 (Obdobja 8), 145-149; Marjan Dolgan, Vprašanje spominske literature, Sodobni slovenski jezik, knjižvnost in literatura, Filozofska fakulteta, Ljubljana 1988 (Obdobja 8), 177-185; Miran Hladnik, Majcnov avtobiografski fragment med spomini in podoživljanjem (Poskus transformacijske literarne analize), Slavistična revija 1989/4, 463-469; Igor Grdina, Vojni dnevnik Edvarda Kocbeka, Slavistična revija 1988/4, 427-436; Franc Zadravec, Zavest o romanu in njegova ,prva oseba" v današnji slovenski literaturi. Prispevek s kolokvija o slovenskem romanu v Jeruzalemu, 22. 6. 1991, Literatura 1991/13, 51-56; Mateja Dimnik, Problem avtobiografske in erotične literature pri Henriju Millerju in njen vpliv na slovenskem, Diplomska naloga, Ljubljana 1988; Igor Škamperle, Dnevnik kot oblika literarnega pisanja, Diplomska naloga, Ljubljana 1990; Igor Grdina, Avtobiografija pri Slovencih od začetkov do nastopa moderne, Magistrsko delo, Ljubljana 1991. 
Ein weiterer, am Beginn der neunziger Jahre verfasster, oft übersehener Beitrag zur Autobiographieforschung stammt von der Germanistin Neva Šlibar. Sie setzt sich in ihrer Dissertation zwar mit der deutschen Biographie auseinander, bezieht aber auch die Autobiographie in ihre Überlegungen mit ein, die auf handlungstheoretischen, strukturalistisch-semiotischen und rezeptionstheoretischen Perspektiven beruhen und eine ähnliche Problematik berühren, wie sie im Zusammenhang mit der slowenischen Autobiographie feststellbar ist (vgl. Šlibar 1991). Zu nennen sind an dieser Stelle auch die germanistischen Beiträge von Vesna Kondrič-Horvat (1998, 2000, 2002) zur autobiographischen Literatur deutschsprachiger Schriftstellerinnen in der Schweiz und Melanija Fabčič (2003), die von den Erkenntnissen der kognitiven Linguistik ausgeht und in ihrer Studie am Beispiel autobiographischer Notate aus der Kriegszeit Text als existentiale Kategorie thematisiert. Der in dieser Arbeit verfolgte inter- und multidisziplinäre Ansatz bringt Theoriemodelle und Fragen zur Sprache, die auch für den Autobiographiediskurs relevant sind.

Seit Mitte der neunziger Jahre reicht die slowenische literaturwissenschaftliche Autobiographieforschung mit den Beiträgen von Neva Šlibar (1995a; 1995b; 1996), Silvija Borovnik (1996; 2003) und Katja Mihurko-Poniž (2003) auch in den Bereich der Genderstudies und Frauenforschung hinein. In zunehmendem Maß werden autobiographische Aspekte außerdem im Zusammenhang von Literatur und Geschlechteridentitäten aufgegriffen. ${ }^{11}$ Auch die Slowenistik außerhalb Sloweniens befasst sich neuerdings mit dem Thema Autobiographie, wie der erzähltheoretische Beitrag der russischen Slowenistin Julija A. Sozina zum slowenischen autobiographischen Roman der neunzehnsiebziger und -achtziger Jahre zeigt, in dem sie die Identität bzw. Nicht-Identität von Autor und Hauptperson beleuchtet (Sozina 2002).

In der slowenischen literaturwissenschaftlichen Essayistik ist die autobiographische Literatur hingegen schon seit den siebziger Jahren ein Thema, wobei Lojze Kovačič zu den meistbesprochenen Autoren zählt. Unter den Essayisten ist auch Janko Kos zu finden, der Kovačičs Schriften in diesem Kontext sehr wohl als Autobiographie oder Fragmente seines Lebenslaufs bezeichnet (Kovačič 1976: 216). Der älteren wie der jüngeren Essayistik ist allerdings gemeinsam, dass sie die Problematik autobiographischen Schreibens meist nur anreißt und die betreffenden Autoren und Texte interpretierend, deutend oder unter referentiellen Gesichtspunkten analysiert. Die Problematik autobiographischen Schreibens thematisieren im übrigen auch viele Autorinnen und Autoren autobiographischer Texte, was die Literaturwissen-

11 Vgl. Brane Mozetič, Literatura na margini?, Časopis za kritiko znanosti, 1997, 253-269; Polona Žagar, Moški in ženska v avtobiografskem romanesknem opusu Vitomila Zupana, Diplomska naloga, Ljubljana: 2002; Suzana Tratnik, Lezbična zgodba - literarna konstrukcija seksualnosti, Ljubljana: ŠKUC, 2004; Tanja Nemanič, Obrobneži v sodobnem slovenskem romanu, Diplomsko delo, Ljubljana 2005; Alojzija Zupan Sosič, Spolna identiteta in sodobni slovenski roman, Primerjalna književnost, 2005/2, 93-113; dies., Homoerotika v najnovejšem slovenskem romanu, Jezik in slovstvo, 2005/3-4, 5-16. 
schaft in Einzelfällen zwar bemerkt hat, doch steht eine genauere Untersuchung dieses Aspekts noch aus.

Fasst man die bisherige Darstellung zusammen, so ist zum einen um 1990 eine erste Welle slowenischer literaturwissenschaftlicher Autobiographieforschung zu verzeichnen, die zeitlich keineswegs zufällig mit den Demokratisierungs- und Unabhängigkeitsprozessen der Republik Slowenien und mit den Individualisierungsbestrebungen in der slowenischen Gesellschaft zusammenfällt. Zum anderen sticht der hohe Anteil studentischer Arbeiten ins Auge. ${ }^{12}$ Da Mitte der neunziger Jahre zunächst wieder weniger Aufsätze zum Thema erscheinen, tragen diese Arbeiten wesentlich zur Kontinuität in der Auseinandersetzung mit Autobiographie bei, die ab 2000 neuerlich einen leichten Aufschwung nimmt. Doch auch die neuesten Tendenzen zeigen, dass die Auseinandersetzung mit Autobiographie im Grunde immer noch eine Domäne der Studierenden ist. ${ }^{13}$ Gerade studentische Arbeiten machen aber auch deutlich, dass ein fundiertes slowenisches Nachschlagewerk zur Autobiographie notwendig wäre, um den nationalen wie internationalen Forschungs- und Diskussionsstand leichter zugänglich zu machen. ${ }^{14}$

12 Nachdem in den späten sechziger, siebziger und frühen achtziger Jahren die Arbeiten Studierender nur vereinzelt auf autobiographische Aspekte im Werk slowenischer Autorinnen und Autoren Bezug nehmen, nimmt deren Zahl in den neunziger Jahren signifikant zu, wie dies aus der Liste der Diplomarbeiten an der Slowenistik in Ljubljana ersichtlich ist. Vgl. http://www.ff.uni-lj.si/hp/dnsk.

13 Vgl. Petra Vidali, Avtobiografski roman, Diplomska naloga, Ljubljana 1998; Drago Meglič, Avtobiografskost v prozi Marjana Rožanca, Diplomska naloga, Maribor 2000; Sašo Krumpak, Vprašanje možnosti vzpostavitve postkolonialnega subjekta ob analizi Soyinkinega avtobiografskega romana Aké - leta otroštva, Diplomsko delo, Ljubljana 2001; Marinka Zoran, Avtobiografske značilnosti v delih Thomasa Wolfa, Magistrsko delo, Ljubljana 2002; Polona Žagar, Moški in ženska v avtobiografskem romanesknem opusu Vitomila Zupana, Diplomska naloga, Ljubljana 2002; Milena Žičkar-Petan, Spomini slovenskih avtoric, Diplomska naloga, Krško 2003; dies., Vloga izkustvenega učenja v avtobiografskih spominih, Diplomsko delo, Ljubljana 2003; Maja Maričić: Avtobiografski roman Zivljenje Arsenjeva Ivana Aleksejeviča Bunina (Prepletanje in povezava preteklosti in sedanjosti $\mathrm{v}$ izboru temeljnih tem in vrednot), B - diplomska naloga, Ljubljana 2003; Zarika Snoj, Avtobiografska pripovedna perspektiva v Proustovem romanu V Swannovem svetu, Razširjeno seminarsko delo iz literarne teorije, Ljubljana 2004; Alenka Spacal, Estetika (avto)portreta. Avtoportretne reprezentacije kot identitetna samoprevpraševanja umetnic, Magistrsko delo, Ljubljana 2004; Mojca Tirš, Gombrowiczeva (avto)poetika v luči njegovih dnevnikov, Dodiplomski seminar, Ljubljana 2004; Marjanca Pušnar, Marija Vogrič, Diplomska naloga, Ljubljana 2004; Tanja Bulajić, Antiutopična literarna fikcija kot družbena realnost in njena kritika, Diplomsko delo, Ljubljana 2005; Irena Lipar, Alma M. Karlin: potovanja in izzivi skrivnostne žene, Diplomsko delo, Maribor 2005; Lučka Drnovšek: Sodobni slovenski potopisni roman, Diplomska naloga, Izlake, 2005.

Diese Notwendigkeit lässt sich am Beispiel von Arbeiten zu autobiographischer Literatur für Kinder und Jugendliche illustrieren, wo weiterhin überholte Definitionen und Merkmale wiedergegeben werden, etwa, dass die „reine Autobiographie“ eine Sonderform der Biographie sei, eine streng sachliche Beschreibung des eigenen Lebens, dass sie zu den didaktischen, subjektiv markierten Schriften historischen Charakters zähle oder gewöhnlich eine größere Nähe zum wissenschaftlichen Schreiben aufweise. Vgl. Valentina Ževma, Avtobiografska pripoved za mladino, Diplomsko delo, Ljubljana 1999, 9; Klara Zidanšek-Otrin, Slovenska mladinska avtobiografska proza, Diplomska naloga, Ljubljana, 
Die Literaturwissenschaft ist, wie erwähnt, nicht allein an der Autobiographiediskussion beteiligt, nimmt aber innerhalb dieser eine Sonderstellung ein, da ihre Erkenntnisse in der Praxis auch für jene Wissenschaften eine wichtige Basis bilden, die ebenfalls autobiographisches Material heranziehen wie etwa die Ethnologie, die Soziologie und verschiedene interdisziplinäre Forschungszweige. Von daher kommt der Literaturwissenschaft im Kontext der Autobiographieforschung auch ein erhöhtes Maß an Verantwortung zu. Andererseits wurden und werden auch in anderen Disziplinen richtungsweisende Methoden erprobt und neue Erkenntnisse gewonnen. Dass hier mitunter Pionierarbeit geleistet wird, veranschaulicht die psychohistorische Untersuchung Alenka Puhars zur Geschichte der Kindheit in Slowenien im 19. Jahrhundert. Die 1982 veröffentlichte und 2004 neu aufgelegte Studie ist nicht nur eine relevante interdisziplinäre Arbeit zur slowenischen Kindheits(auto)biographieund Frauenforschung, sondern beinhaltet auch die erste Bibliographie slowenischer Erinnerungsliteratur. Das Quellenmaterial ist zwar nach den Rubriken Memoiren und Zeugnisse gegliedert, enthält aber viele literarische Texte, die in der literaturwissenschaftlichen Auseinandersetzung mit der Autobiographie von zentraler Bedeutung sind (Puhar 2004, 429-434). ${ }^{15}$

Im Zusammenhang mit der Autobiographieforschung in Geschichte, Kultur- und Sozialanthropologie, Ethnologie, Linguistik, Pädagogik, Gerontologie, Kriminologie, Psychologie, Psychoanalyse und anderen Gesellschafts- und Humanwissenschaften (vgl. Ramšak 2000: 217-238) spielen zwei Zugänge eine wesentliche Rolle: Oral history und die ,autobiographische Methode“. Da Oral history an jeglichen Lebensgeschichten interessiert ist, kommt es hier zwar oft zu Überschneidungen biographischer und autobiographischer Forschung, doch ist dieser Bereich in der Autobiographiediskussion schon deshalb nicht zu vernachlässigen, weil er sich vielfach auch auf literarische Quellen stützt. Vor allem unter Ethnologen ist seit den neunziger Jahren ein stetig wachsendes Interesse an der Auswertung autobiographischen Materials zu bemerken. ${ }^{16}$ Von dort ausgehend entwickelte sich um 2000 eine rege

2000, 11; Jansa Černic, Tone Partljič. Humorni vzorec v avtobiografskih delih za mladino, Diplomsko delo, Koper 2003, 42-43).

15 Die Rubrik der Memoiren umfasst u. a. Texte von L. Adamič, J. Alešovec, F. Bevk, F. Finžgar, C. Golar, I. Hribar, G. Jirku-Stridsberg, M. Kmet, I. Lah, F. Levstik, J. Mlakar, M. Murko, L. Pesjak, A. Prepeluh, I. Regent, J. Stritar, I. Šorli, J. Trdina, L. Tuma, I. Valjavec, J. Vidmar und F. Milčinski, die Zeugnisse u. a. L. Adamič, I. Cankar, D. Kette, Z. Kveder, M. Šipek und Prežih.

16 Am Beginn dieser Entwicklung steht ein 1997 von den Ethnologinnen Marija Makarovič und Mojca Ramšak in Kärnten veranstaltetes Symposion, das die Bewertung von Lebensgeschichten zum Inhalt hatte (vgl. Zablatnikov dan 1997). Makarovič ist auch hauptverantwortlich für die seit 1993 in Klagenfurt erscheinende Reihe Tako smo živeli, die aktuell 12 Bände umfasst, und betreibt ähnliche Aktivitäten auch in Slowenien. Mojca Ramšak, Initiatorin des 2001 in Ljubljana gegründeten Zentrums für biographische Forschungen (Center za biografske raziskave) befasst sich mit theoretischen und forschungsgeschichtlichen Fragen sowie Lebensgeschichten von Kärntner Slowenen (Ramšak 1994; 2000; 2003; Ramšak - Mitro 2003). 
Diskussion um die autobiographische Methode im eigenen Fach und in den verwandten Disziplinen, in deren Rahmen auch die unausweichliche Frage gestellt wurde: Was ist Autobiographie? ${ }^{17}$ Die Diskussion machte auf die unterschiedlichen Auffassungen und Erwartungen im Zusammenhang mit der Definition und Auswertung von Autobiographien durch die Ethnologie und andere Wissenschaften aufmerksam. Ein gemeinsamer Nenner, was die autobiographische Methode und Autobiographie letztlich seien, konnte nicht gefunden werden (Čebulj-Sajko 2003).

Slowenische Ethnologen neigen dazu, die Autobiographie in der übergeordneten „biographischen Gattung“ eingebettet zu sehen, was nicht weiter problematisch wäre, würde dies nicht gerade unter Verweis auf slowenische literaturwissenschaftliche Quellen geschehen (Ramšak 2003: 17, 34-35). Gegenüber der Literaturwissenschaft hat die slowenische Ethnologie aber gewiss den Vorteil, dass sie jegliches (auto)biographische Material zu ihrem Forschungsgegenstand macht, da ästhetische oder qualitative Kriterien keinerlei Hindernis darstellen. Infolge dessen ist die slowenische Ethnologie sogar in der Lage, in der Anwendung der (auto)biographischen Methode eine hundertjährige Tradition herzuleiten, die - vor allem die ältere Zeit betreffend wiederum auf literarischen Texten gründet (Ramšak 2003: 76).

Die Arbeiten der ethnologisch orientierten (Auto)Biographieforschung zeigen darüber hinaus, dass diese Forschungen in den slowenischen Minderheiten und Communities außerhalb Sloweniens ein reiches Betätigungsfeld gefunden haben. ${ }^{18}$ Das ethnische und nationale Moment rückt oft deutlich in den Mittelpunkt und scheint die vormals in der slowenischen Literaturwissenschaft betonte nationale Komponente nun gleichsam für sich zu beanspruchen. Ein beträchtlicher Teil dieser Arbeiten orientiert sich überdies an traditionellen positivistischen und historiographischen Denkmustern, sei es, um diese zu ergänzen, neue Perspektiven einzubringen oder sie kritisch zu hinterfragen. Dabei wird meist von der Existenz eines ganzheitlichen, selbstreferentiellen Subjekts ausgegangen, das in der Lage ist, sein Leben zu strukturieren und ihm eine spezifische Bedeutung beizumessen. Die Parallelen zu einem unkritischen, konventionellen Autobiographiebegriff könnten deutlicher nicht sein.

Auch in der slowenischen Soziologie sind in den letzten Jahren eine Reihe von Arbeiten entstanden, die Autobiographien, Autobiographik und autobiographische Quellen heranziehen (vgl. Rener 1996). Wie breit die Auswertung (auto)biographischen Materials angelegt sein kann, zeigt Mojca Urek, die in ihrer Studie über das

17 Stellvertretend sei auf den Runden Tisch hingewiesen, der im Mai 1999 im Rahmen des Historischen Seminars des ZRC an der Slowenischen Akademie der Wissenschaften in Ljubljana stattfand und an dem vor allem Wissenschafterinnen aus verschiedenen geisteswissenschaftlichen Disziplinen teilnahmen (Avtobiografska metoda 1999).

18 Dazu zählen die Arbeiten der Germanistin Jerneja Petrič (1987) über Auswandererautobiographien von Slowenen in den USA, Auswandererautobiographien von Slowenen in Australien (Čebulj-Sajko 1999) und Studien von Marija Jurić-Pahor zur Identität der Slowenen in Italien und Kärnten (Jurić-Pahor 1993; 2000). 
Erzählen, Schreiben und Schildern in der Sozialarbeit mündliche, schriftliche und literarische Quellen, Biographien und Autobiographien für ihre Untersuchung heranzieht sowie auf die Bedeutung des Erzählens von Geschichten in gesellschaftlichen Bewegungen und bei der Konstituierung öffentlicher, kollektiver und persönlicher Erinnerung eingeht. Urek kritisiert (mit Judith Okley) außerdem, dass die Autobiographie als Gattung von alten Konventionen determiniert werde und auf Maßstäbe zurück gehe, die vom eurozentristischen und literarischen Kanon wie den Konfessionen eines Augustinus, Rousseau oder John Stuart Mill gesetzt worden seien. Andere Autobiographien, etwa jene der Arbeiterklasse, habe man aus der Sozialgeschichte ausgeschlossen, jene von scheinbar untalentierten und ,unberufenen“ Frauen aus dem literarischen Genre verbannt und ihnen eine geringe oder keine ästhetische oder kulturelle Bedeutung zugeschrieben (Urek 2005: 225-226, 229-230).

Die Vielfalt der Forschungsmöglichkeiten einer Auseinandersetzung mit Autobiographie zeigen des weiteren Arbeiten, die sich mit der Analyse ethnisch gemischter Familien, mit pädagogischer Arbeit oder auch mit Aspekten der slowenischen Unabhängigkeit befassen. ${ }^{19}$

Zusammenfassend lässt sich sagen, dass man heute durchaus von einer slowenischen Autobiographieforschung sprechen kann, dass aber diese Forschung stark segmentiert ist. Sie findet meist in den einzelnen Wissenschaftsdisziplinen, ja an einzelnen Instituten und Institutionen statt und nur selten in einem Fächer- und Institutionen übergreifenden Rahmen. Dies wirft die Frage auf, warum im relativ kleinen slowenischen Raum die Slowenistik, Komparatistik, Germanistik, Ethnologie, Soziologie usw. bei der Auseinandersetzung mit der Autobiographie und Autobiographik erst allmählich voneinander Notiz zu nehmen beginnen.

Folgt man Andrej Pleterski, der 2002 konstatierte, dass man in den humanistischen Wissenschaften immer wieder auf ,Vergesslichkeit“" beim Zitieren stoße, dass die Kultur des fachlichen Dialoges ,darnieder" liege, scheint das Problem Teil einer im slowenischen Wissenschaftsdiskurs allgemein verbreiteten Symptomatik zu sein, würden doch gemeinsame Forschungsziele nur mit „Zähneknirschen“ gesetzt, lieber sei man ein zufälliges Häufchen von Individuen. Überdies sei die Sozialisation wissenschaftlicher Erkenntnisse gering, Spott und Ignoranz seien eine häufige Reaktion auf Neuerungen (Pleterski 2004: 39). Ähnlich kritisierte Zoran Stančič, dass die ohnehin kleinen Forschungsgruppen schlecht miteinander verbunden seien und es fast keine institutionelle Zusammenarbeit gebe. Auch die fehlende internationale Rezeption und Durchschlagskraft slowenischer Forschungen führte er als großes Manko an (Stančič 2004: 64).

19 Vgl. Mateja Sedmak, Avto/biografski pristop k proučevanju etnično mešanih zakonskih zvez, Socialno delo 2001/2-4, Ljubljana, 181-190; Milena Žičkar-Petan, Vloga izkustvenega učenja v avtobiografskih spominih, Diplomsko delo, Ljubljana 2003; Radoslav Sumer, Avtobiografski pogledi na slovensko osamosvajanje, Diplomsko delo, Maribor 2004. 
Im Bereich der Autobiographieforschung ist die Situation besonders prekär, denn die internationale Diskussion läuft nahezu ohne slowenische Beteiligung ab. ${ }^{20}$ Allein mit der speziellen slowenischen Situation, vor allem der langen Eingebundenheit in den jugoslawischen Staatsverband, in das sozialistische System, lässt sich die Absenz slowenischer Autobiographien und autobiographischer Forschung im internationalen Kontext nicht schlüssig erklären, selbst wenn die kulturpolitische Doktrin der Nachkriegszeit dem autobiographischen Schreiben nicht förderlich war. Diese These widerlegt das Beispiel der lebendigen, auch international rezipierten Autobiographieforschung in Kroatien. ${ }^{21}$ Ausschlaggebend dürften vielmehr die Nachwirkungen des Festhaltens der slowenischen Literaturwissenschaft an einem traditionell ästhetisch geprägten Literaturmodell sein, das die Autobiographie nicht kanonisierte und mit anderen, ebenfalls erst in den letzten Jahren von der Literaturwissenschaft „entdeckten“ nichtfiktionalen „Mischformen“ wie dem Essay, dem Brief, dem Tagebuch und Reisebeschreibungen aus dem Bereich der Literatur ausgeschlossen hatte. Dies trifft, mit Einschränkungen, zwar auch auf die westeuropäischen Literaturen zu, wo als musterhaft kanonisierte autobiographische Texte die Aufnahme neuerer Autobiographik vereitelten, doch haben sich dort um das Thema Autobiographie längst verschiedene Forschungszweige entwickelt und etabliert.

Im slowenischen Kontext ist in dieser Hinsicht trotz der zahlreichen neueren Arbeiten ein erheblicher Rückstand zu verzeichnen. Zwar begann sich Marjan Dolgan in seiner Funktion als Mitarbeiter des ZRC bei der Slowenischen Akademie der Wissenschaften und Künste 1996 mit der Problematik der slowenischen Erinnerungsprosa und der autobiographischen Prosa eingehender zu befassen (Dolgan 1998: 40-41), doch wandte er sich bald anderen Themen zu. Seine Kollegin Alenka Koron befasst sich wiederum vor allem mit dem engeren Bereich des Romans als Autobiographie. Auch haben sich die bisherigen Ergebnisse der slowenischen Autobiographiediskussion bislang kaum auf die Ebene der Literaturtheorie, der Literaturgeschichte, der Lehrbücher und Lexika ausgewirkt. Sieht man von den Arbeiten Grdinas und einigen Diplomarbeiten ab, gibt es keine epochenübergreifenden, diachronen Studien zum autobiographischen Schreiben. Kurz: in vielen Bereichen der

${ }^{20}$ So haben im deutschsprachigen Raum bislang nur die Forschungen der Germanistin Neva Šlibars zur Theorie und Wirkungsgeschichte der Biographie (vgl. Šlibar 1995a; 1997) und im englischsprachigen zuletzt auch jene von Alenka Koron (2006) Spuren hinterlassen.

21 Vgl. Viktor Žmegač, Književnost i zbilja. Zagreb: Školska knjiga, 1982; Andrea Zlatar, Istinito, lažno, izmišljeno. Ogledi o fikcionalnosti, Zagreb: Hrvatsko filozofsko društvo, 1989; Mirna Velčić, Otisak priče. Intertekstualno proučavanje autobiografije, Zagreb: August Cesarec, 1991; Vinko Brešić, Autobiographies by Croatian writers, Zagreb, Dubrovnik: P. E. N. Croatian Centre: Most, 1993; Magdalena Medarić (Hg.), Autotematizacija u književnosti, Zagreb: Zavod za znanost o književnosti 1996; Vinko Brešić, Autobiografije hrvatskih pisaca, Zagreb: AGM, 1997; Andrea Zlatar, Autobiografija u Hrvatskoj, Zagreb: Matica hrvatska, 1998; dies., Ispovijest i životopis. Srednjovjekovna autobiografija, Zagreb: Izdanja Antibarbarus, 2000; Helena Sablić Tomić, Intimno i javno. Suvremena hrvatska autobiografska proza, Zagreb: Zdenko Ljevak, 2002; Andrea Zlatar, Tekst, tijelo, trauma. Ogledi o suvremenoj ženskoj književnosti, Zagreb: Naklada Lijevak, 2004. 
slowenischen Autobiographieforschung gilt es noch Vorarbeiten zu leisten und Lücken zu schließen. Angesichts der längst inter- und intradisziplinären Auseinandersetzung mit dem Thema ist davon auszugehen, dass eine umfassende Studie zur slowenischen Autobiographie, die das Kriterium der Literarität hintanstellt, nicht nur nach innen wirken, sondern der slowenischen Autobiographieforschung auch dabei helfen könnte, in den internationalen Diskurs zu finden und von ihm wahrgenommen zu werden.

Die beachtliche Anzahl neuerer Arbeiten stellt jedenfalls in Aussicht, dass der Stellenwert von Autobiographie und Autobiographik weiterhin wachsen und damit bald in einem angemessenen Verhältnis zur diesbezüglichen Textproduktion stehen wird. Damit sollte, ähnlich wie schon im deutschen Sprachraum, auch im slowenischen Kontext der Zustand überwunden werden, wo die Praxis des Schreibens ihrer Theorie weit voraus ist (Finck 1995: 290).

\section{Literatur}

Avtobiografska metoda 1999: Avtobiografska metoda. Pogovor o njeni uporabnosti v različnih znanstvenih disciplinah in tematskih sklopih. Okrogla miza v okviru historičnega seminarja ZRC SAZU, 10. 5. 1999, Glasnik Slovenskega etnološkega društva 39/3-4, 62-75, 116-117

Bajt 1993:

D. Bajt, Pišem, torej sem. Priročnik za pisanje, Maribor

Belšak 2003:

A. Belšak, Žanri v slovenski daljši prozi, in: Slovenski roman, Mednarodni simpozij Obdobja (= Obdobja 21), Ljubljana, 151-160

Bernik 1983:

F. Bernik, Tipologija Cankarjeve proze, Ljubljana

Bernik 1987:

F. Bernik, Ivan Cankar. Monografska študija, Ljubljana

Bernik - Dolgan 1988: F. Bernik - M. Dolgan, Slovenska vojna proza, 1941-1980, Ljubljana

Borovnik 1996:

Borovnik 2003:

S. Borovnik, Pišejo ženske drugače?, Ljubljana

Čebulj-Sajko 1999: B. Cebulj-Sajko, Etnologija in izseljenstvo. Slovenci po svetu kot

S. Borovnik, Romani sodobnih slovenskih pisateljic, Slavistična revija $51 / 3,285-299$

Čebulj-Sajko 2003: predmet etnoloških raziskav v letih 1926-1993, Ljubljana

Dolinar 1978:

B. Čebulj-Sajko, Ali vemo, kaj je avtobiografija, Argo 1, 119-122

Fabčič 2003:

D. Dolinar, Pozitivizem v literarni vedi, Ljubljana

M. Fabčič, Der Text als existenziale Kategorie. Expliziert am Beispiel der Textsorte ,autobiographisches Notat", Maribor

Finck 1995:

A. Finck, Subjektbegriff und Autorschaft. Zur Theorie und Geschichte der Autobiographie, in: Pechlivanos, Miltos u. a. (Hg.), Einführung in die Literaturwissenschaft, Stuttgart - Weimar, 283-293

Grdina 1991: I. Grdina, Avtobiografija pri Slovencih od začetkov do nastopa moderne, Magisterarbeit, Ljubljana

Grdina 1994:

I. Grdina, Avtobiografska književnost pri Slovencih v dvajsetem stoletju, Dissertation, Ljubljana

Hladnik 1989: $\quad$ M. Hladnik, Majcnov avtobiografski fragment med spomini in podoživljanjem (Poskus transformacijske literarne analize), Slavistična revija 37/4, 463-469

Jurić-Pahor 1993: $\quad$ M. Jurić-Pahor, Zur ethnischen Identität der Sloweninnen und Slowenen in Kärnten und in der Provinz Triest, Klagenfurt/Celovec - Trieste/Trst

Jurić-Pahor 2000: $\quad$ M. Jurić-Pahor, Narod, identiteta, spol, Trst 
Juvan 2002:

M. Juvan, Žanrska identiteta in medbesedilnost, Primerjalna književ-

Juvan 2006: nost 25/1, 9-25

Kmecl 1967:

M. Juvan, Literarna veda v rekonstrukciji. Uvod v sodobni študij literature, Ljubljana

$\begin{array}{ll}\text { Kmecl 1976: } & \text { M. Kmecl, Mala literarna teorija, Ljubljana } \\ \text { Kondrič-Horvat 1998: } & \text { V. Kondrič-Horvat, Infragestellung von gängigen Denk-, Verhaltens- }\end{array}$

B. Paternu - H. Glušič-Krisper - M. Kmecl, Slovenska književnost 1945-1965 I. Lirika in proza, Ljubljana und Sprachmustern. Dominierende Themen, Motive und Schreibweisen bei den Schriftstellerinnen in der deutschsprachigen Schweiz der 70er und 80er Jahre, Vestnik 32/1-2, 379-409

Kondrič-Horvat 2000: V. Kondrič-Horvat, Fiktionalisierung der eigenen Biographie durch Sprachexperimente. Zu Erica Pedretti, Acta neophilologica 33/1-2, 35-47

Kondrič-Horvat 2002: V. Kondrič-Horvat, Fiktion und Phantasie als Autobiographie. Zu Aglaja Veteranyis Roman Warum das Kind in der Polenta kocht, Vestnik 36/1-2, 463-467

Koron 1991: A. Koron, Prispevki za žanrsko skico Kovačičevega pisateljskega opusa. Prispevek s kolokvija o slovenskem romanu v Jeruzalemu, 22. 6. 1991, Literatura 3/13, 62-74

Koron 1995:

A. Koron, Vrata realnosti: etuda o Kovačičevem romanu Resničnost, in: Lojze Kovačič, Resničnost, Ljubljana, 159-173

Koron 1998:

A. Koron, Nočni planet: Kovačičeva Sporočila v spanju, sanje in interpretacije sanj, in: Lojze Kovačič, Interpretacije, 12-48

Koron 1999:

A. Koron, Pogled za očmi: o romanu Deček in smrt Lojzeta Kovačiča, in: Lojze Kovačič, Deček in smrt, Ljubljana, 367-407

Koron 2003a:

Koron 2003b:

A. Koron, Roman kot avtobiografija, in: Slovenski roman, Mednarodni simpozij Obdobja (= Obdobja 21), Ljubljana, 191-200

Koron 2006:

A. Koron, Avtobiografija, fikcija, roman: o možnostih žanra ,roman kot avtobiografija', Primerjalna književnost 26/2, 65-86

A. Koron, Fiction, autobiography and memoir intertwined: the writings of Frank McCourt's and Lojze Kovačič, in: Sabine CoelschFoisner/Wolfgang Görtschacher (Hg.), Fiction and autobiography, Frankfurt am Main, 155-166

Kos 1976:

J. Kos. Spremna beseda, in: Lojze Kovačič, Resničnost, Ljubljana, 217-226

Kos 1983:

J. Kos, Roman, Ljubljana

Mihurko-Poniž 2003:

Mitrović 1967: sti, Ljubljana

Niggl 1998:

M. Mitrović-Gleščić, Avtobiografski elementi v delih Juša Kozaka, Sodobnost, 15/3, 299-311

Petrič 1987:

Niggl, G. (Hg.), Die Autobiographie. Zu Form und Geschichte einer literarischen Gattung, Darmstadt [1989]

Pirjevec 1991:

Pleterski 2004:

Pregelj 1936:

Puhar 2004:

J. Petrič, Avtobiografije slovenskih izseljencev v Združenih državah Amerike, Dissertation, Ljubljana

D. Pirjevec, Filozofija in umetnost in drugi spisi, Ljubljana

A. Pleterski, Zaprta znanost: Odgovorna znanost začne pri sebi, in: Za odprto znanost, Ljubljana, 39-40

I. Pregelj, Osnovne črte iz književne teorije, Ljubljana

A. Puhar, Prvotno besedilo življenja. Oris zgodovine otroštva na Slovenskem v 19. stoletju, Nachdruck, Ljubljana [1982]

Ramšak 1994:

M. Ramšak, Renesansa blagih metod. O raziskovanju življenjske zgodbe - viru za preučevanje identitete posameznika in skupnosti v času in prostoru, Časopis za zgodovino in narodopisje 65/2, 347-355

Ramšak 2000: M. Ramšak, Ustna zgodovina in življenjske zgodbe na poti k etnologiji, in: Kolesar s Filozofske, Ljubljana, 217-238

Ramšak 2003: $\quad$ M. Ramšak, Portret glasov. Raziskave življenjskih zgodb v etnologiji - na primeru koroških Slovencev, Ljubljana 
Ramšak - Mitro 2003: M. Ramšak - V. Mitro, Projekt „Ženski spomin“. Od ustne zgodovine do interpretacije biografskega gradiva (Bratislava 28. 2. 2003 - 1. 3. 2003), Traditiones 32/2, 279-281

Rener 1996: $\quad$ T. Rener, Avto/biografije v sociologiji in ženskih študijah, Teorija in praksa, 33/5, 764-774

Sedmak 2001: $\quad$ M. Sedmak, Avto/biografski pristop k proučevanju etnično mešanih zakonskih zvez, Socialno delo 40/2-4, 181-190

Sozina 2002:

J. A. Sozina, Avtor in glavna literarna oseba v slovenskem avtobiografskem romanu sedemdesetih in osemdesetih let 20. stoletja, Slavistična revija 50/2, 199-202

Stančič 2004: $\quad$ Z. Stančič, Slovenska znanost v mednarodnih primerjavah. Dobri, sla-

Škamperle 1990: bi ali nekje vmes, in: Za odprto znanost, Ljubljana, 63-65

Šlibar 1991:

I. Škamperle, Dnevnik kot oblika literarnega pisanja, Diplomarbeit, Ljubljana

Šlibar 1995a:

N. Šlibar, Struktur und Funktionen der literarischen Biographie. Versuch einer Theorie biographischer Texte, Doktorarbeit, Ljubljana

N. Šlibar, Biographie. Autobiographie. Annäherungen, Abgrenzungen, in: Michaela Holdenried (Hg.), Geschriebenes Leben. Autobiographik von Frauen, Berlin, 390-401

Šlibar 1995b:

N. Šlibar, Žensko življenjepisje - večkratno izobčen diskurz $=$ Women's Biography Writing - Repeatedly Banished Discourse, Časopis za kritiko znanosti 23/175, 94-99

Šlibar 1996:

N. Šlibar, Ženski (avto)biografski diskurz, O njegovi subverzivnosti in potrebi po uzaveščanju njegovih pravil, Delta 2/1-2, 64-77

Šlibar 1997: $\quad$ N. Šlibar, Biographie, in: Horst Brunner (Hg.), Literaturwissenschaftliches Lexikon. Grundbegriffe der Germanistik, Berlin, Sp. 52a-53b

Stuhec 2000:

Trdina 1978: M. Štuhec, Naratologija. Med teorijo in prakso, Ljubljana

Urek 2005:

S. Trdina, Besedna umetnost II, Ljubljana [1958]

M. Urek, Zgodbe na delu. Pripovedovanje, zapisovanje in poročanje v socialnem delu, Ljubljana

Zablatnikov dan 1997: Zablatnikov dan in mednarodni etnološki simpozij. Vrednotenje življenjskih pričevanj / Evaluation of biographies / Die Bewertung von Lebenszeugnissen, Zablatnikov dan in mednarodni etnološki simpozij, 24.-25. maja 1997, Tinje/Tainach, Austria; a cura di Marija Makarovič, Mojca Ramšak, Pisa

Zadravec 1991: $\quad$ F. Zadravec, Zavest o romanu in njegova ,prva oseba“ v današnji slovenski literaturi. Prispevek s kolokvija o slovenskem romanu v Jeruzalemu, 22. 6. 1991, Literatura 3/13, 51-56

Zadravec 1997: $\quad$ F. Zadravec, Slovenski roman dvajsetega stoletja. Prvi analitični del, Murska Sobota - Ljubljana

Zadravec 2002: $\quad$ F. Zadravec, Slovenski roman dvajsetega stoletja. Drugi analitični del in nekaj sintez, Murska Sobota - Ljubljana

Zadravec 2005: $\quad$ F. Zadravec, Slovenski roman dvajsetega stoletja. Tretji analitični del in sinteze, Murska Sobota - Ljubljana

\author{
Andreas Leben \\ Institut für Slawistik der Universität Wien \\ Universitätscampus AAKH, Hof 3 \\ Spitalgasse 2, A-1090 Wien \\ andreas.leben@univie.ac.at
}


